\title{
Mechanical properties of lettuce (Lactuca sativa L.) for horticultural machinery
}

\author{
design
}

\author{
Reuel Scherrer Xavier ${ }^{1 \oplus}$, Cezário Benedito Galvão ${ }^{2} \oplus$, Ruan Lessa Rodrigues ${ }^{1 \oplus}$, Angel Pontin Garcia²๑, Daniel Albiero ${ }^{2 *} \odot$
}

\begin{abstract}
'Universidade Federal do Ceará/CCA - Depto. de Engenharia Agrícola, Av. Mister Hull, 2977 - 60440-900 - Fortaleza, CE - Brasil.

2Universidade Estadual de Campinas/FEAGRI - Conselho Integrado de Infraestutura Rural, Campus Zeferino Vaz, Av. Candido Rondon, 501 - 13083-875 - Campinas, SP - Brasil.

*Corresponding author <daniel.albiero@gmail.com >
\end{abstract}

Edited by: Thiago Libório Romanelli

Received August 14, 2020

Accepted May 25, 2021
ABSTRACT: Currently, there is a growing need to develop machines that replace human work efficiently and effectively in horticulture with the same sensibility of the human hand, since horticultural foods are notably very fragile to handle and process, especially considering machinery and systems. This work aimed to determine the mechanical properties of lettuce (Lactuca sativa L.) variety Crispa. For that, two methodologies were used in the field of material engineering: one specific for polymers and composites - the standard ASTM D3039 - Standard test method for tensile properties of polymer matrix composite materials (ASTM, 2002a) and the other specific for plastic films - the ASTM 882 - Standard test method for tensile properties of thin plastic sheeting (ASTM, 2002b). The tests were adapted for lettuce samples. The mechanical properties for the leaf and stem of head lettuce (var. Crispa) were obtained with appropriate statistical rigor, which can be considered valid initial estimates for dimensioning mechanisms and systems of machines for horticultural works specialized in lettuce. These properties provide fundamental engineering parameters to design machine elements that interact with biological materials, allowing to develop devices that generate minor damage to biological structures in lettuce.

Keywords: tensile test, biological material, modulus of elasticity

\section{Introduction}

Modern agriculture worldwide has evidenced the issue of lack of human labor to carry out operations related to planting, cultivation, and especially harvesting horticultural products. This is a technical, social, and demographic problem (Marinoudi et al., 2019) and is essentially linked to the pressing need to develop machines that can replace human work efficiently and effectively as it were carried out by human hands (Albiero, 2019; Albiero et al., 2020; Melo et al., 2013).

Horticultural foods are notably very fragile to handle and process with mechanical, thermal, electrical, optical, and even sound parameters that are too complex to measure (Mohsenin, 1970). These parameters are directly linked to intrinsic physical characteristics regarding product quality, such as shape, size, volume, surface area, density, porosity, color, and appearance, which are associated to machine designing. Thus, the process of designing a machine for this purpose requires an analysis of product behavior concerning conditions generated by handling processes (Mohsenin, 1986).

However, despite the increasing importance of knowledge of the physical-mechanical parameters of these horticultural products, little is known about the base properties in mechanical terms of many species widely used in the world. Therefore, this study aims to contribute to reducing this information gap about lettuce (Lactuca sativa L.), more specifically about mechanical properties.

According to Melo et al. (2019), in the context of designing agricultural machinery, a major obstacle refers to the adequacy of engineering methodologies with the needs and particularities of agricultural products. For example, adapting mechanisms and mechanical systems to develop a machine that manipulates lettuce to its morphology and mainly to the resistance limits of the biological material because. Lettuce leaves are fragile and must be handled with care (Yamaguchi, 1983). Therefore, the knowledge of the lettuce mechanical properties becomes crucial to dimension the forces applied by the apparatuses that encounter the product, because it comprises in the harvesting subprocess considering the moment of removing the lettuce head from the soil without damaging its structure, both in terms of the whole head and individual leaves.

\section{Materials and Methods}

\section{Theorical Background}

Much of the complexity regarding the measurement of these properties in lettuce is because it is a biological material thus alive. According to Mohsenin (1986), each unit of this material differs widely from another, even considering divisions of the same weight and geometry. The living material causes lettuce to change its shape, respiration, and cell sensitivity constantly. This living material is also directly influenced by the time series of the environment where humidity, temperature, oxygen level, food supply, and energy consumption vary daily as well as factors internal to products related to biochemistry.

These facts confer a considerable deviation to a biological material in terms of mechanical behavior concerning common materials for use and treatment 
in engineering. The first significant deviation refers to linearity of the phenomena related to the loading and strain of these materials. According to Ashby and Jones (2007), one of the leading mechanical properties of any material is the modulus of elasticity (E) which can be defined as a proportionality constant between the applied stress and the imposed strain on a material. One way to determine the $\mathrm{E}$ value is to consider that behavior is linear to find the slope of the straight line that represents the load applied to the material due to the strain it undergoes.

The major problem with biological materials is that a straight line is not obtained when loading and measuring their strains due to their non-linear behavior. Some materials, such as wood, have linear regions; however, lettuce has a completely non-linear behavior. Ashby and Jones (2007) state that biological materials are composites of polymers. Although their properties are different for different polymeric materials, biological materials are all composed of long molecules with a backbone of covalently bonded carbon atoms; thus, these materials suffer fluency when loading increases with time. (Ashby and Jones, 2007)

According to Mohsenin (1986), this temporal dependence results in a behavior called visco-elastic. Lettuce is a viscoelastic material and must be treated with appropriate methodologies to obtain its mechanical properties. In this work, two classic methods were chosen in the area of engineering of polymeric and composite materials: the standard of American Society for Testing and Materials (ASTM) D3039 - Standard test method for tensile properties of polymer matrix composite materials (ASTM, 2002a) and ASTM 882 for plastic films - Standard test method for tensile properties of thin plastic sheeting. In addition, these tests were adapted for lettuce samples (ASTM, 2002b).

The results obtained for the mechanical properties of the lettuce were: the Modulus of Elasticity - Yield Secant Method, the Modulus of Elasticity - Chord Method, Rupture Limit Stress Yield Limit Stress, Ultimate Limit Stress, Strain at Rupture, Strain at Yield, Ultimate Strain, Resilience to the Secant Modulus of Elasticity, Resilience to the Chord Modulus of Elasticity and Toughness. Therefore, this information is essential for the proper dimensioning of the mechanisms related to lettuce and is available in the literature regarding the design of specific agricultural machines for leafy vegetables.

\section{Experiment sites and material}

The experiment with the stem was carried out in Fortaleza - Ceará, Brazil $\left(3^{\circ} 44^{\prime} \mathrm{S}\right.$, longitude $38^{\circ} 34^{\prime} \mathrm{W}$, altitude $16 \mathrm{~m}$ ) and in Campinas - SP, Brazil (leaf tests) $\left(22^{\circ} 48^{\prime} \mathrm{S}, 47^{\circ} 03^{\prime} \mathrm{W}\right.$, altitude 695$)$. Stems of lettuce heads and leaves (Lactuca sativa L. var. Crispa) were used. The experiments with the leaves were carried out in another laboratory, as they required equipment with a smaller force scale to have sensitivity to capture the stress and deformation data perpetrated in the leaves.

\section{Experimental planning}

The statistical planning adopted followed a completely random design. The minimum number of samples to ensure data normality followed the methodology of Montgomery (2004) because considering a $\beta$ error of $10 \%$ and the use of the two-tailed operational characteristic chart allowed obtaining five samples per repetition. Considering five repetitions per treatment, the total number of samples is 25 for each treatment. There were three treatments for the lettuce head stem with a storage temperature of $5^{\circ} \mathrm{C}$ : Fresh stem (T1), stem with one day of refrigeration (T2), and stem with two days of refrigeration (T3). An experiment was carried out with whole fresh leaves (L). Figures 1 and 2 refer to the diagram of the lettuce leaf and head stem with their adopted terminologies, respectively.

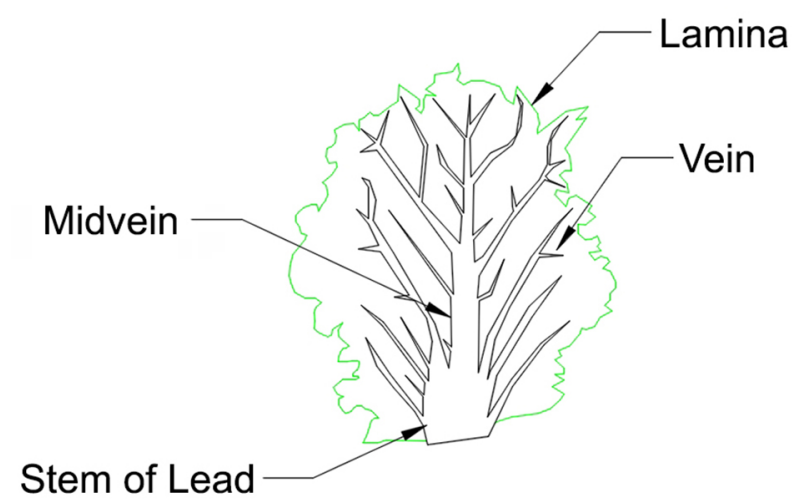

Figure $\mathbf{1}$ - Schematic diagram of the lettuce leaf with an indication of the terminology adopted for plant structures. Lettuce leaf diagram and adopted terminology. Source: own data.

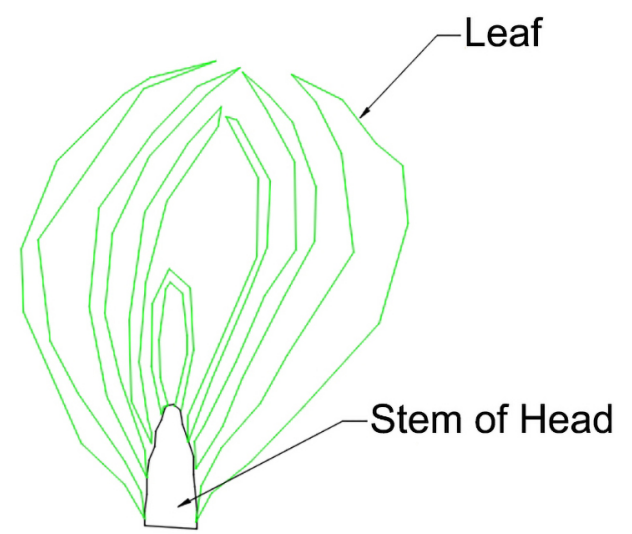

Figure 2 - Schematic diagram of the lettuce head stem with an indication of the terminology adopted for plant structures. Source: own data. 


\section{Methodological procedures}

The methodology adopted for the analysis of the stems was the use of fresh material (harvested on the day) and material with one and two days under refrigeration at $5{ }^{\circ} \mathrm{C}$ also to verify the influence of the refrigeration time on its properties. The stem samples were obtained by carefully detaching the surrounding leaves, making cylindrical samples of $70 \mathrm{~mm}$ in length, where the tensile tongs of a Universal Machine for Mechanical Tests (UMMT) were attached to the $10 \mathrm{~mm}$ of each end (Figure 3) to carry out the tensile test for the stem and the leaf, according to ASTM D3039 and ASTM D882.

The initial extension used to calculate strain was calibrated to $50 \mathrm{~mm}$ in the stem and $15 \mathrm{~mm}$ in the leaf. Thirty-seven samples (37 specimens) per treatment (per day) were used in the stem test, with one example for each lettuce head. Twenty-five samples (25 specimens) were used for the whole leaves and choosing the first head

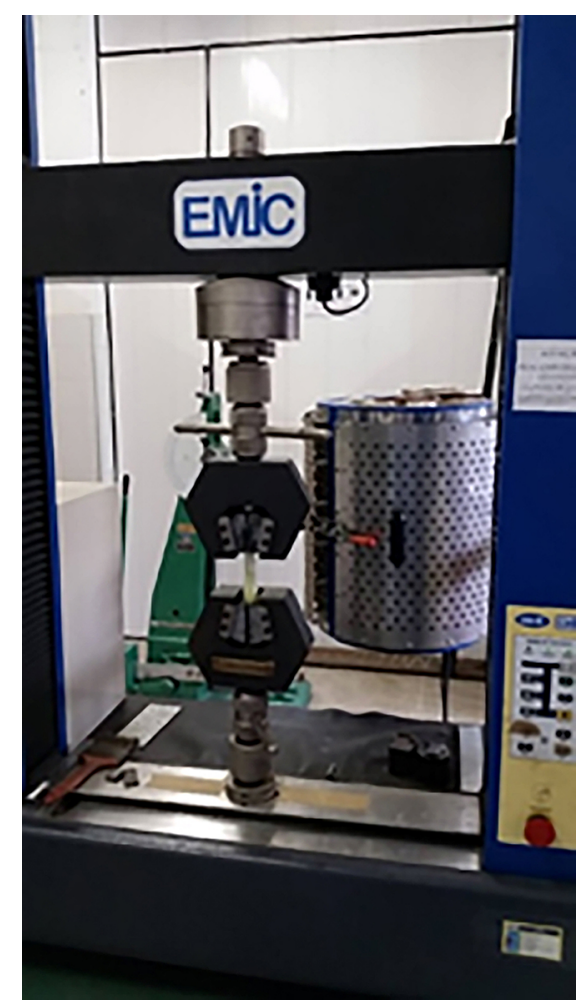

Figure 3 - Universal machine UMMT for testing mechanical properties of biological material with a stem being tested. leaf. The fresh material from the leaves of the evaluated plants was dried in an oven at $65{ }^{\circ} \mathrm{C}$ until constant weight, according to the method in Souza et al. (2015). The characterization of the samples is shown in Table 1.

The samples were tested at a speed of $2 \mathrm{~mm} \mathrm{~min}^{-1}$. The following mechanical properties obtained for the leaf stem and the whole leaf were: modulus of elasticity by the yield secant method according to ASTM D882, modulus of elasticity by the chord method according to ASTM D3039, resilience, and toughness according to Rodrigues and Martins (2005), yield limit, rupture limit, and fracture limit of the material.

According to Rodrigues and Martins (2005), resilience can be considered as the material ability to absorb energy when deformed in the elastic domain and can be obtained by Eq. (1):

$U_{R}=\frac{\sigma_{e}^{2}}{2 . E}$

where: $U_{R}$ is resilience $(\mathrm{MPa}), \sigma e$ is yield strain $(\mathrm{MPa})$, and $E$ is the modulus of elasticity of the material (MPa). Note: Resilience of materials was calculated considering the modulus of elasticity by the secant method and by the chord method.

According to Rodrigues and Martins (2005), toughness can be considered the material ability to absorb energy when deformed in the plastic domain and it is obtained by Eq. (2):

$U_{T} \cong \frac{\sigma_{e}+\sigma_{R}}{2} . \epsilon_{f}$

where: $U_{T}$ is toughness (MPa), $\varepsilon f$ is strain to fracture, $\sigma e$ is yield strain (MPa), and $\sigma R$ is strain to fracture (MPa).

As a qualitative comparison, a stress versus strain chart was constructed for a whole leaf and another for the leaf stem. The experiments chosen for plotting these charts came closest to the ultimate average stress of all experiments performed. The procedures were presented from the elaboration of these charts according to ASTM D3039 to obtain the modulus of elasticity by the chord method and by the yield secant method, as well as the Tensile Energy to Break (TEB), according to ASTM D882 by the Eq. (3):

$T E B=\int_{0}^{\epsilon_{t}} S \cdot d \epsilon$

where: TEB is the tensile energy needed to break ( $\mathrm{J}$ $\left.\mathrm{m}^{-3}\right) ; \mathrm{S}$ is the stress at break $(\mathrm{MPa}) ; \varepsilon$ is the strain; $\varepsilon$ is

Table 1 - Geometric and physical characteristics of lettuce samples for each treatment, average value \pm Standard Deviation (SD).

\begin{tabular}{|c|c|c|c|c|c|c|c|c|}
\hline Treatment & $\begin{array}{c}\text { Number of Leafs } \\
\text { per Head }\end{array}$ & $\begin{array}{c}\text { Number } \\
\text { of Samples }\end{array}$ & $\begin{array}{l}\text { Leaf } \\
\text { Height }\end{array}$ & $\begin{array}{l}\text { Leaf } \\
\text { Width }\end{array}$ & $\begin{array}{c}\text { Leaf Thickness } \\
60 \% \text { Height }\end{array}$ & $\begin{array}{l}\text { Leaf Fresh } \\
\text { Weight }\end{array}$ & $\begin{array}{c}\text { Leaf Dry } \\
\text { Weight }\end{array}$ & $\begin{array}{c}\text { Stem } \\
\text { Diameter }\end{array}$ \\
\hline & & Leaves & & $-\mathrm{mm}-$ & - & 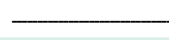 & - & $\mathrm{mm}$ \\
\hline $\mathrm{T} 1$ & $46 \pm 1$ & 37 & $189 \pm 1.54$ & $210 \pm 2.05$ & $0.76 \pm 5.15$ & $8.56 \pm 15.41$ & $0.47 \pm 14.31$ & $18 \pm 3$ \\
\hline $\mathrm{T} 2$ & $44 \pm 2$ & 37 & $191 \pm 1.40$ & $209 \pm 1.84$ & $0.68 \pm 2.52$ & $8.17 \pm 14.53$ & $0.38 \pm 10.46$ & $21 \pm 4$ \\
\hline T3 & $44 \pm 2$ & 37 & $200 \pm 1.14$ & $215 \pm 1.91$ & $0.77 \pm 1.72$ & $8.64 \pm 16.40$ & $0.49 \pm 9.40$ & $20 \pm 3$ \\
\hline $\mathrm{L}$ & $45 \pm 1$ & 25 & $186 \pm 1.34$ & $186 \pm 25$ & $0.72 \pm 0.09$ & $8.45 \pm 13.98$ & $0.42 \pm 25.41$ & $20 \pm 3$ \\
\hline
\end{tabular}


the strain at rupture. The procedure adopted to obtain TEB was to find the area under stress versus strain curve using the full-scale drawing of that curve in the AutoCAD 2019 Software and the MEDIRGEOM/AREA command.

\section{Experimental apparatus}

Some fixation adaptations were made to test the whole leaf in a small lathe of $647.76 \mathrm{~g}$. Two aluminum U-beams covered with synthetic leather strips were attached to this lathe to avoid injuries to the lettuce samples and not alter the result since the biological material referring to the whole leaf is more sensitive (Figure 4). Tightness of these $U$ beams was distributed evenly over the whole leaf surface and the lathe was prepared to prevent it sliding, which could compromise the result (Figure 5).

The EMIC did not have a scale background to obtain the force values obtained for the whole leaf; therefore, a $50 \mathrm{~N}$ load cell with of sensitivity $2,000 \mathrm{mV} / \mathrm{V}$ ) was adapted and fixed to the upper grips of the machine (Figure 5). Figure 5 presents the rupture moment of the lettuce leaf, showing how it was fixed in the UMMT machine, using the lathe with the load cell also clutched to the device so that the fastened leaf is stressed.



Figure 4 - Lathe adaptation with a felt holder to fix the lettuce leaf.

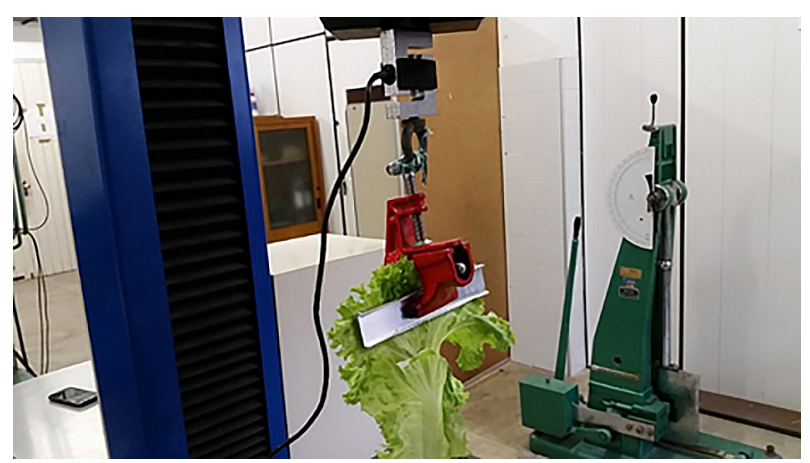

Figure $\mathbf{5}$ - Experimental setup for testing the lettuce leaves with the adapted lathe pulling a specimen. Note the rupture of the leaf far from the pressing elements, which proves the adequacy of the adaptation.

\section{Statistical evaluations}

The data on leaf stems and whole leaves were analyzed using the MINITAB 16 program, in which descriptive statistics were made. Symmetry and kurtosis of data distribution were used to evaluate data normality. According to Montgomery (2004), symmetry and kurtosis values between -2 and 2 characterize a normal data distribution. Thus, after confirming data normality, the analysis of variance (ANOVA) was performed using the F statistic to assess the significance between treatments related to leaf stems, where a BoxPlot chart was built with the data collected and to evaluate trends in data distribution of leaf stems.

\section{Results and Discussion}

\section{Stem Mechanical Properties}

After carrying out the experiments, the average values of the requests on leaf stems are shown in Table 2.

The evaluation of the coefficient of variation $(\mathrm{CV})$ shows that all variables are high, as according to Albiero et al. (2012), typical characteristic in biological materials. Nevertheless, measurements of symmetry and kurtosis of variables are between 2 and -2 , indicating possible normal data distribution (Montgomery, 2004).

The average values of the stem mechanical properties of the lettuce head are presented in Table 3. All measurements of symmetry and kurtosis indicate normal data distribution.

All these parameters had a coefficient of variation above $30 \%$, which is consistent with data from other agricultural products, such as tomatoes with a CV ranging from 35 to $75 \%$ (Zdunek and Kurenda, 2013), wheat with $26 \%$ (Moya et al., 2013), and potato with $9.7 \%$ (Finney and Hall, 1967). Although high coefficients of variation are not a good sign in statistical terms, considering the intrinsic variability in living products such as food, Albiero et al. (2012) states that it is possible to consider more extensive tolerance ranges physical-mechanical parameters. In this context, a good indication for the use of classical statistical methods is the assumption of normality in the data, which, in this specific work, considers the data distribution as a test of normality obtained by symmetry and kurtosis (Snedecor and Cochran, 1989), limiting the range between -2 and 2 for normality (Montgomery, 2004).

Based on the premise of data normality, a singlefactor analysis of variance was performed to evaluate whether for a significant difference in the ultimate stress regarding the time after harvest. The first days was considered the first harvest day and the two subsequent days the days when the samples were kept in a cold chamber (Table 4).

Given the significance presented, it is clear that the harvest time within the range of three days (harvest day and two subsequent days in a cold chamber), did not influence the stem mechanical properties of the lettuce 
Table 2 - Experimental data on force and strain of the stem for each treatment (day after harvest).

\begin{tabular}{|c|c|c|c|c|c|c|c|c|}
\hline & $\begin{array}{l}\text { Ultimate } \\
\text { Force }\end{array}$ & $\begin{array}{l}\text { Ultimate } \\
\text { Strain }\end{array}$ & $\begin{array}{l}\text { Yield } \\
\text { Force } \\
\end{array}$ & $\begin{array}{l}\text { Yield } \\
\text { Strain }\end{array}$ & $\begin{array}{l}\text { Rupture } \\
\text { Force }\end{array}$ & $\begin{array}{l}\text { Rupture } \\
\text { Strain }\end{array}$ & $\begin{array}{c}\text { Diameter } \\
\text { Stem }\end{array}$ & Area \\
\hline & $\mathrm{N}$ & $\mathrm{mm}$ & $\mathrm{N}$ & $\mathrm{mm}$ & $\mathrm{N}$ & $\longrightarrow \mathrm{m}$ & 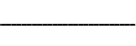 & $\mathrm{mm}^{2}$ \\
\hline & \multicolumn{8}{|c|}{ Day 1} \\
\hline Mean & 89.18 & 0.06575 & 82.88 & 0.06022 & 65.91 & 0.0847 & 18.622 & 278.9 \\
\hline $\mathrm{SD}^{*}$ & 34.42 & 0.02196 & 34.93 & 0.02053 & 30.76 & 0.0247 & 2.938 & 90.5 \\
\hline Kurtosis & -0.7 & 0.02 & -0.83 & 0.41 & -0.57 & -0.28 & -0.03 & 0.74 \\
\hline Skew & 0.46 & 0.36 & 0.42 & 0.43 & 0.28 & 0.09 & 0.67 & 1 \\
\hline Minimum & 37.65 & 0.02417 & 33.5 & 0.02308 & 17.04 & 0.03933 & 14 & 153.9 \\
\hline Maximum & 167.7 & 0.12412 & 160.15 & 0.11853 & 143.73 & 0.14455 & 26 & 530.9 \\
\hline Variance & $1,184.44$ & 0.00048 & $1,220.06$ & 0.00042 & 945.94 & 0.00061 & 8.631 & 8,198.8 \\
\hline \multirow[t]{2}{*}{$\mathrm{CV}^{* *}(\%)$} & 38.59 & 33.4 & 42.14 & 34.09 & 46.66 & 29.17 & 15.78 & 32.46 \\
\hline & \multicolumn{8}{|c|}{ Day 2} \\
\hline Mean & 107.77 & 0.0741 & 101.18 & 0.06893 & 81.67 & 0.09408 & 21.568 & 377.6 \\
\hline $\mathrm{SD}^{*}$ & 36.19 & 0.02966 & 36.43 & 0.02851 & 33.7 & 0.028 & 4.011 & 136.1 \\
\hline Kurtosis & 1.29 & 0.27 & 0.9 & 0.45 & -0.46 & 0.2 & -1.04 & -0.98 \\
\hline Skew & 0.79 & 0.71 & 0.64 & 0.86 & -0.09 & 0.68 & -0.02 & 0.24 \\
\hline Minimum & 27.38 & 0.02199 & 23.45 & 0.021 & 2.53 & 0.04899 & 14 & 153.9 \\
\hline Maximum & 208.8 & 0.14295 & 199.4 & 0.13652 & 141.82 & 0.16623 & 29 & 660.5 \\
\hline Variance & 1309.95 & 0.00088 & 1327.31 & 0.00081 & 1135.84 & 0.00078 & 16.086 & 18528 \\
\hline \multirow[t]{2}{*}{$\mathrm{CV}^{* *}(\%)$} & 33.58 & 40.03 & 36.01 & 41.36 & 41.27 & 29.76 & 18.6 & 36.05 \\
\hline & \multicolumn{8}{|c|}{ Day 3} \\
\hline Mean & 100.18 & 0.06658 & 94.79 & 0.06658 & 72.86 & 0.08627 & 20.324 & 331.4 \\
\hline $\mathrm{SD}^{*}$ & 38.39 & 0.02664 & 37.84 & 0.02664 & 34.82 & 0.02913 & 3.028 & 97.2 \\
\hline Kurtosis & -0.27 & -0.2 & -0.3 & -0.1 & -0.14 & -0.26 & -0.73 & -0.65 \\
\hline Skew & 0.16 & 0.78 & 0.08 & 0.88 & 0.14 & 0.77 & 0.03 & 0.31 \\
\hline Minimum & 27.38 & 0.02897 & 20.61 & 0.02897 & 6.7 & 0.04415 & 15 & 176.7 \\
\hline Maximum & 181.4 & 0.12697 & 173.24 & 0.12697 & 147.66 & 0.1535 & 26 & 530.9 \\
\hline Variance & $1,473.56$ & 0.00071 & $1,431.64$ & 0.00071 & $1,212.27$ & 0.00085 & 9.17 & $9,450.7$ \\
\hline $\mathrm{CV}^{* *}(\%)$ & 38.32 & 40.01 & 39.91 & 40.01 & 47.79 & 33.77 & 14.9 & 29.33 \\
\hline
\end{tabular}

${ }^{*}$ Standard Deviation; * ${ }^{*}$ Coefficient of Variation.

head. Although the storage time in biological materials affects the modulus of elasticity, as aging increases the value, there was no statistically significant significance in this fact in our experiment. An explanatory hypothesis is that cold storage slowed down the vegetable structures of lettuce to the point where there was no significant difference in three days after harvest.

A Boxplot chart for the ultimate stress was constructed to present this fact graphically (Figure 6).

Figure 7 shows the behavior concerning the stem stress and strain of the lettuce head in the sample with the ultimate strength value $(90.55 \mathrm{~N})$ close to the average value $(89.18 \mathrm{~N})$ on the first day.

The use of time-based mathematical models based on the viscoelastic equations is the most accurate and indicated for biological material (Dal Fabbro et al., 2020). Nevertheless, they are complex models based on tensor calculations of the stress and strain varying over time, as they demand an advanced treatment in terms of shear, poison, elasticity, and bulk modules since they are variable in time and in deformation rates. However, in this work, we intended to use standard methodologies of polymeric materials science (ASTM D3039 and ASTM D882). These methodologies are simplifications of the viscoelastic

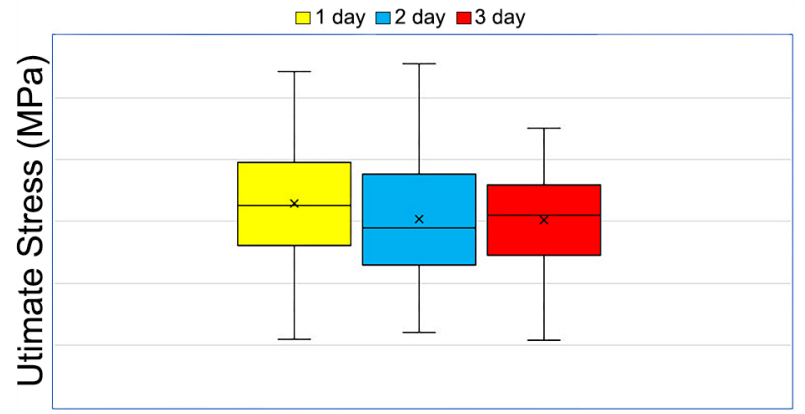

Figure 6 - Boxplot chart showing the influence of harvest time at the ultimate stress for the stem. Cross inside the rectangle: average; middle horizontal line of the rectangle: median.

models; however, they are helpful because they allow obtaining the values of the elasticity modules quickly and reliably, within adequate safety factors.

According to the ASTM D3039 standard, the modulus of elasticity is calculated as the slope of the straight line defined by points (g) and (f). These points are found as a function of the normalized absolute strain of $0.001(\mathrm{~g})$ and 0.003 (f), called the chord modulus. 
Table 3 - Mechanical properties of lettuce stem for each treatment (day after harvest).

\begin{tabular}{|c|c|c|c|c|c|c|c|c|}
\hline & $\begin{array}{l}\text { Ultimate } \\
\text { Stress }\end{array}$ & $\begin{array}{l}\text { Yield } \\
\text { Stress }\end{array}$ & $\begin{array}{l}\text { Rupture } \\
\text { Stress }\end{array}$ & $\begin{array}{c}\text { Chord Modulus } \\
\text { D3039 }\end{array}$ & $\begin{array}{c}\text { Secant Modulus } \\
\text { D882 }\end{array}$ & $\begin{array}{c}\text { Resilience- } \\
\text { Chord Modulus }\end{array}$ & $\begin{array}{c}\text { Resilience- } \\
\text { Secant Modulus }\end{array}$ & Toughness \\
\hline & \multicolumn{8}{|c|}{$-\mathrm{MPa}-2$} \\
\hline \multicolumn{9}{|c|}{ Day 1} \\
\hline Mean & 0.3296 & 0.3012 & 0.2419 & 15.508 & 4.871 & 0.003101 & 0.009874 & 0.027718 \\
\hline SD* & 0.1042 & 0.0946 & 0.0945 & 5.985 & 1.88 & 0.001242 & 0.003953 & 0.01343 \\
\hline Kurtosis & -0.25 & -0.67 & -0.62 & -0.67 & -0.7 & -0.33 & -0.13 & -0.08 \\
\hline Skew & -0.12 & -0.28 & -0.21 & 0.66 & 0.46 & 0.03 & 0.02 & 0.77 \\
\hline Minimum & 0.1087 & 0.1038 & 0.0377 & 6.547 & 2.056 & 0.000804 & 0.002559 & 0.058665 \\
\hline Maximum & 0.5423 & 0.4665 & 0.416 & 29.163 & 9.16 & 0.005715 & 0.018196 & 0.005547 \\
\hline Variance & 0.0109 & 0.0089 & 0.0089 & 35.819 & 3.533 & 0.000002 & 0.000016 & 0.000185 \\
\hline $\mathrm{CV}^{* *}(\%)$ & 31.61 & 31.4 & 39.07 & 38.59 & 38.59 & 40.04 & 40.04 & 48.45 \\
\hline \multicolumn{9}{|c|}{ Day 2} \\
\hline Mean & 0.304 & 0.281 & 0.2267 & 18.74 & 5.886 & 0.002343 & 0.00746 & 0.02811 \\
\hline $\mathrm{SD}^{*}$ & 0.0985 & 0.0847 & 0.0912 & 6.29 & 1.977 & 0.001231 & 0.003921 & 0.0138 \\
\hline Kurtosis & 0.09 & -0.01 & -0.23 & 1.09 & 1.29 & -0.79 & -0.39 & -0.09 \\
\hline Skew & 0.51 & 0.25 & 0.01 & 0.79 & 0.97 & 0.55 & 0.35 & 0.87 \\
\hline Minimum & 0.1196 & 0.1046 & 0.0126 & 4.76 & 1.495 & 0.000459 & 0.001462 & 0.009 \\
\hline Maximum & 0.5559 & 0.4816 & 0.4152 & 36.31 & 11.404 & 0.005181 & 0.016494 & 0.06042 \\
\hline Variance & 0.0097 & 0.0072 & 0.0083 & 39.61 & 3.908 & 0.000002 & 0.000015 & 0.00019 \\
\hline $\mathrm{CV}^{* *}(\%)$ & 32.4 & 30.16 & 40.25 & 33.58 & 33.58 & 52.55 & 52.55 & 49.1 \\
\hline \multicolumn{9}{|c|}{ Day 3} \\
\hline Mean & 0.3027 & 0.2841 & 0.219 & 17.42 & 5.472 & 0.002463 & 0.007843 & 0.02569 \\
\hline $\mathrm{SD}^{*}$ & 0.0809 & 0.0786 & 0.0845 & 6.68 & 2.097 & 0.000864 & 0.002751 & 0.0122 \\
\hline Kurtosis & 0.39 & 0.32 & -0.08 & -0.27 & -0.2 & -0.07 & -0.05 & 1.39 \\
\hline Skew & -0.58 & -0.66 & -0.39 & 0.16 & 0.11 & 0.14 & 0.19 & 1.07 \\
\hline Minimum & 0.1076 & 0.1028 & 0.0191 & 4.76 & 1.495 & 0.000541 & 0.001724 & 0.00516 \\
\hline Maximum & 0.4501 & 0.4299 & 0.3884 & 31.55 & 9.908 & 0.004288 & 0.013651 & 0.06102 \\
\hline Variance & 0.0065 & 0.0062 & 0.0071 & 44.56 & 4.396 & 0.000001 & 0.000008 & 0.00015 \\
\hline $\mathrm{CV}^{* *}(\%)$ & 26.73 & 27.67 & 38.58 & 38.32 & 38.32 & 35.07 & 35.07 & 47.48 \\
\hline
\end{tabular}

${ }^{*}$ Standard Deviation; ${ }^{*}$ Coefficient of Variation.

Table 4 - Analysis of variance of the ultimate stress of stem.

\begin{tabular}{lrrrrr}
\hline & D.F. & SS & SM & F & P \\
\hline Factor & 2 & 0.0171 & 0.00855 & 0.95 & 0.391 \\
Error & 108 & 0.97563 & 0.00903 & & \\
Total & 110 & 0.99273 & & & \\
\hline
\end{tabular}

*Standard Deviation; * ${ }^{*}$ Coefficient of Variation.

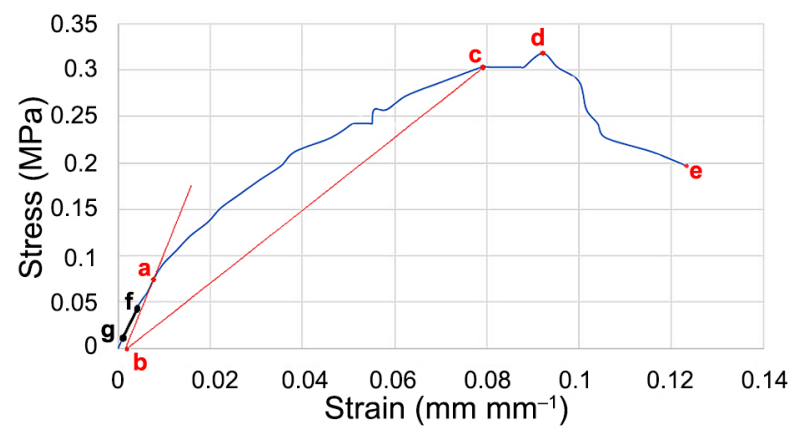

Figure 7 - Stress / Strain diagrams of lettuce head stem with the ultimate strength value $(90.55 \mathrm{~N})$ close to the average value $(89.12 \mathrm{~N}$ ) on the first day. ASTM D3039 standard, line (f-g); ASTM D882 standard, lines $(a-b)$ and $(b-c)$. Point $(d)$ is the ultimate stress, and point (e) is rupture stress.
According to the ASTM D882 standard, the modulus of elasticity is calculated in function of the correction relative to the point of the greatest inflection of the nonlinear curve (a); at this point, a straight correction line is drawn according to the slope of the curve; the extension of this line meets the correction point (b), which is the origin of a straight line that connects to the point (c) defined as the yield stress of the material; the slope of the straight line (b) - (c) is called Secant Modulus. Points (d) and (e) are the ultimate stress and rupture stress, respectively.

The data in Table 3 show that the chord modulus is about three times greater than the secant modulus. This fact represents a difficulty for a designer because, depending on the chosen modulus, there is a representative difference regarding the stem mechanical behavior of the lettuce head due to requests and damages. Literature studies show that lettuce behavior, except for the scale of values, is among the behavior of composites evaluated by the D3039 standard (Balachandar et al., 2019; Kazemi et al., 2019) and the behavior of plastic films considered by the D882 standard (Pérez-Arauz et al., 2019; Soontarapa and Arnusan, 2019). 
Therefore, it is important not to fix only one methodology to obtain the mechanical properties, mainly because the structural components of lettuce are viscoelastic, which requires data evaluation according to strain and time of the request. Assessment of the possible mechanisms to have contact with biological material in a machine demonstrates that, in some systems, strain and application time of the force is entirely different from others, for example, cutting systems versus transportation systems.

\section{Mechanical properties of lettuce leaf}

Table 5 shows the ultimate force at ultimate strain for the lettuce leaf. The coefficient of variation (CV) of all leaf variables, as well as of the stem, was high, but the measurements of symmetry and kurtosis are within the normal limits of 3 to -3 .

The average values of lettuce leaf mechanical properties are presented in Table 6. All measurements of symmetry and kurtosis indicate normal data distribution.

All these parameters had a coefficient of variation above $30 \%$, some above $60 \%$, which is consistent with data from other leafy agricultural products, such as cabbage with a CV around 33 \% (Kohyama et al., 2008). Data distribution was considered standard because symmetry and kurtosis ranged from -3 to 3 , confirming the normality hypothesis.
Figure 8 shows the stress and strain behavior for lettuce leaf in the sample with the ultimate strength value $(9.01 \mathrm{~N})$ close to the average value $(11.07 \mathrm{~N})$. The procedures to obtain the leaf mechanical properties were the same adopted for the stem and followed the recommendations of the ASTM D3039 and ASTM D882 standards. The data in Table 6 show that the chord modulus is also more significant than the value of Secant modulus by around two times, and in relation to the stem, four times.

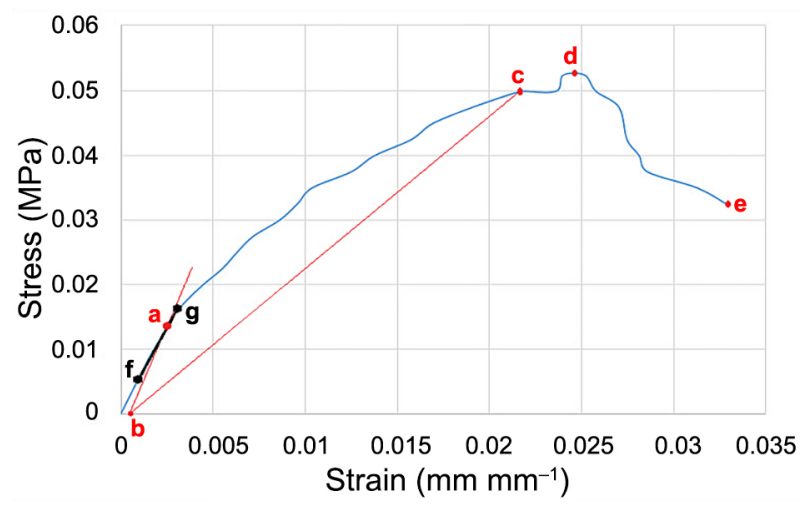

Figure 8 - Stress/Strain diagrams of lettuce leaf with the ultimate force value $(9.01 \mathrm{~N})$ close to the average value (11.07 N). ASTM D3039 standard, line (f-g); ASTM D882 standard, lines (a-b) and $(b-c)$. Point (d) is the ultimate stress, and point (e) is rupture stress.

Table 5 - Experimental Data force and strain of the Leaf.

\begin{tabular}{|c|c|c|c|c|c|c|c|c|c|}
\hline & $\begin{array}{l}\text { Ultimate } \\
\text { Force }\end{array}$ & $\begin{array}{l}\text { Ultimate } \\
\text { Strain }\end{array}$ & $\begin{array}{l}\text { Yield } \\
\text { Force }\end{array}$ & $\begin{array}{l}\text { Yield } \\
\text { Strain }\end{array}$ & $\begin{array}{l}\text { Rupture } \\
\text { Force }\end{array}$ & $\begin{array}{l}\text { Rupture } \\
\text { Strain }\end{array}$ & Thickness & Width & Area \\
\hline & $\mathrm{N}$ & $\mathrm{mm}$ & $\mathrm{N}$ & $\mathrm{mm}$ & $\mathrm{N}$ & 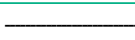 & $-\mathrm{mm}$ & - & $\mathrm{mm}^{2}$ \\
\hline Mean & 11.071 & 0.03025 & 9.238 & 0.02307 & 8.581 & 0.06119 & 0.7211 & 186.92 & 134.78 \\
\hline$S D^{*}$ & 3.587 & 0.01334 & 3.752 & 0.01079 & 3.192 & 0.02308 & 0.099 & 25.67 & 36.24 \\
\hline Kurtosis & 0.68 & -0.55 & 1.78 & -0.06 & -1.41 & -0.94 & -0.58 & -0.68 & -0.79 \\
\hline Skew & 0.45 & 0.63 & 0.86 & 0.9 & 0.14 & 0.66 & -0.38 & -0.18 & -0.13 \\
\hline Minimum value & 5.617 & 0.00757 & 4.075 & 0.00704 & 3.43 & 0.03357 & 0.5208 & 135 & 70.31 \\
\hline Maximum value & 20.783 & 0.05514 & 20.45 & 0.04625 & 13.709 & 0.10935 & 0.868 & 225 & 195.3 \\
\hline Variance & 12.868 & 0.00018 & 14.08 & 0.00012 & 10.192 & 0.00053 & 0.0098 & 658.91 & 1313.01 \\
\hline $\mathrm{CV}^{* *}(\%)$ & 32.4 & 44.08 & 40.62 & 46.79 & 37.2 & 37.71 & 13.73 & 13.73 & 26.4 \\
\hline
\end{tabular}

D.F. $=$ Degree of Freedom; $S S=$ Square Sum; $S M=$ Square Mean; $F=$ Statistical F; $P=$ Significance.

Table 6 - Mechanical properties of the lettuce leaf.

\begin{tabular}{|c|c|c|c|c|c|c|c|c|}
\hline & $\begin{array}{l}\text { Ultimate } \\
\text { Stress }\end{array}$ & $\begin{array}{l}\text { Yield } \\
\text { Stress }\end{array}$ & $\begin{array}{l}\text { Rupture } \\
\text { Stress }\end{array}$ & $\begin{array}{c}\text { Chord Modulus } \\
\text { D3039 }\end{array}$ & $\begin{array}{c}\text { Secant Modulus } \\
\text { D882 }\end{array}$ & $\begin{array}{c}\text { Resilience- } \\
\text { Chord Modulus }\end{array}$ & $\begin{array}{c}\text { Resilience- } \\
\text { Secant Modulus }\end{array}$ & Toughness \\
\hline Mean & 0.0878 & 0.07454 & 0.06426 & 5.075 & 2.233 & 0.00066 & 0.00150 & 0.00527 \\
\hline$S D^{*}$ & 0.0384 & 0.04067 & 0.02128 & 1.611 & 0.708 & 0.000351 & 0.000799 & 0.00332 \\
\hline Kurtosis & -1.11 & -0.48 & -1.12 & 0.7 & 0.68 & -1.11 & -1.01 & 0.8 \\
\hline Skew & -0.24 & 0.74 & -0.27 & 0.51 & 0.45 & -0.24 & -0.19 & 1.17 \\
\hline Minimum & 0.033472434 & 0.02823 & 0.02744 & 1.931 & 0.824 & 0.000171 & 0.0004 & 0.001181 \\
\hline Maximum & 0.160954684 & 0.1579 & 0.09653 & 7.146 & 3.049 & 0.000854 & 0.002001 & 0.012286 \\
\hline Variance & 0.001540608 & 0.00165 & 0.00045 & 1.521 & 0.277 & 4.357E-08 & $2.397 \mathrm{E}-07$ & 8.395E-06 \\
\hline $\mathrm{CV}^{* *}(\%)$ & 43.79410965 & 54.56 & 33.12 & 32.4 & 31.7 & 53.27 & 47.94 & 63.03 \\
\hline
\end{tabular}

${ }^{*}$ Standard Deviation; * ${ }^{*}$ Coefficient of Variation. 


\section{Operational recommendations and considerations}

This study recommends using the chord modulus when the strains caused to the leaf and stem of the lettuce head are minor. In terms of machinery design, this condition refers to systems that have contact with the stem and leaf through mechanical elements that carry out the transport, handling, internal contact systems to the machines, packaging, storage, and orientation.

When mechanisms generate great strain to the stem or leaf of the lettuce head, the Secant modulus is strongly recommended because the chord modulus aggravates mechanical force request that can exceed two to three times the limits of biological material. In this case, the main systems refer to the cutting, plucking, defoliation, elevation, attrition, fragmentation, and separation mechanisms.

The imposed strain rate on lettuce is crucial to evaluate the values of the mechanical properties. According to Mohsenin (1986), agricultural and biological materials have non-linear viscoelastic behavior. This means that they are very close to viscoplasticity, where the stress and strain magnitude is essential to evaluate the material behavior, mainly at the moment of force unloading in which the sample may undergo permanent strain (Mohsenin, 1970).

According to Dal Fabbro and Gazzola (2018), considering the effects of the strain rate on fresh fruits, the stress/strain ratio is independent of time; however, after a certain period of force application, the curve slope is different. The action of the viscous component causes this different curve (Dal Fabbro and Gazzola, 2018).

According to Zeltmann et al. (2017), the stressstrain curves of polymers are much more sensitive to strain and temperature rates than in ceramics and metals, because their curves have a greater dependence on time (Andrade, 2017). In this context, lower rates decrease the modulus of elasticity and other mechanical properties, such as yield stress, while higher rates increase the values.

The mechanical properties obtained in this study were limited to the strain rate of $2 \mathrm{~mm} \mathrm{~min}^{-1}$. Thus, the data presented here can be considered as minimum limit values since it is difficult for any operational machine to have actions that demand lower strain rates. In the case of activities with higher rates, a detailed analysis on the increase significance in the modulus of elasticity in the design is necessary. Higher rates represent higher values of the curve slope, indicating that the biological material undergoes less strain due to the same stress, thus, also increasing the yield limit. In this hypothesis, a higher strain rate represents an increase in the safety factor of the operation, considering possible damage to lettuce.

This fact can be clarified by the evaluation of Tensile Energy to Break (TEB) according to the ASTM D882 standard, which is the stress energy needed to break. Using the diagrams in Figures 6 and 7 and integrating the curve to the rupture point, a TEB of $27,831 \mathrm{~J} \mathrm{~m}^{-3}$ for the stem of the lettuce head and 2108 $\mathrm{J} \mathrm{m}^{-3}$ for the lettuce leaf is obtained, which means that the energy to break the stem is 13.20 times greater than that for the leaf.

It is easier to break a lettuce leaf than the lettuce head stem; therefore, these values indicate that minor variations in the shape of the stress/strain curve can significantly modify the energy needed to generate the break. In a simulation, increasing the secant modulus of elasticity by $10 \%$ (adjusting the curve in the AutoCAD software) and assuming an increase in yield stress of $10 \%$, the TEB for the stem becomes $32,790 \mathrm{~J} \mathrm{~m}^{-3}$, that is, there is an increase of $17.81 \%$ in the energy needed to break the material. As for the leaf, an equal increase in the secant modulus and in yield stress raises the TEB to $2798 \mathrm{~J} \mathrm{~m}^{-3}$, increasing by $32.73 \%$.

This increase in the strain rate has a limit because, after a specific value, the action of the mechanical element affects plastic strain and fragile rupture in the biological material, an undesirable condition. Thus, the designer could use the values presented in this study as an initial estimate, which should be calibrated and refined to the specific strain rate of the design.

\section{Conclusions}

The mechanical properties for the leaf and the stem of the lettuce head (Lactuca sativa L var. Crispa) were obtained with appropriate statistical rigor, which can be considered as valid initial estimates for the dimensioning of mechanisms and systems of machines for horticultural works specialized in lettuce. The chord modulus of elasticity for stem for each day after harvest was $15.51 \mathrm{MPa}$ (first day), 18.74 MPa (second day), and 17.42 MPa (third day), while the chord modulus of elasticity for leaf was 5.07 $\mathrm{MPa}$. The secant modulus of elasticity for stem for each day after harvest was 4.82 $\mathrm{MPa}$ (first day), 5.88 $\mathrm{MPa}$ (second day), and 5.47 $\mathrm{MPa}$ (third day), while the secant modulus of elasticity for leaf was 2.33 $\mathrm{MPa}$. The experiments showed no influence on the mechanical properties of the stem within three days after harvesting the lettuce heads.

Operational considerations regarding the strain rate applied to the biological material were carried out and the data presented in this study should be used with care because minimum values must be considered in designing horticultural machinery. The strain rate significantly influenced the results obtained.

It is recommended to choose the modulus of elasticity, secant, or chord, depending on the specific design of the machinery mechanisms and systems. However, the chord modulus is suggested as a safer choice when the strains caused by the machine to the leaf and stem of the lettuce head are minor, while the secant modulus is recommended for major strains. 


\section{Acknowledgments}

To the National Council for Scientific and Technological Development (CNPq - process number 304931/2015-2), to the Coordination for the Improvement of Higher Education Personnel (CAPES - process number 2982/2013), and the Ceará Foundation for the Support of Scientific and Technological Development (FUNCAP process number AE1-0079-000250100/13) for financial resources and scholarships. Thanks to Prof. Dr. Marcelo José Gomes da Silva of Mechanical Testing Laboratory of the Department of Metallurgical Engineering of the Federal University of Ceará for permission to use the laboratory equipment.

\section{Authors' Contributions}

Conceptualizaton: Albiero, D. Data acquisition: Xavier, R.S.; Rodrigues, R.L. Data analysis: Galvão, C.B.; Garcia, A.P. Design of methodology: Albiero, D. Writing and editing: Albiero, D.

\section{References}

Albiero, D. 2019. Agricultural robotics: a promising challenge. Current Agriculture Research Journal 7: 1-3. https://doi. org/10.12944/CARJ.7.1.01

Albiero, D.; Silva Maciel, A.J.; Milan, M.; Monteiro, L.A.; Mion, R.L. 2012. Proposal of using exponentially weighted moving average for studies about longitudinal distribution of seeds. Revista Ciência Agronômica 43: 55-65.

Albiero, D.; Paulo, R.L.D.; Félix Junior, J.C.; Santos, J.D.S.G.; Melo, R.P. 2020. Agriculture 4.0: a terminological introduction. Revista Ciência Agronômica 51: e20207737. https://doi.org/10.5935/1806-6690.20200083

American Society for Testing and Materials [ASTM]. 2002a. ASTM D3039 - Standard Test Method for Tensile Properties of Polymer Matrix Composite Materials. ASTM, West Conshohocken, PA, USA.

American Society for Testing and Materials [ASTM]. 2002b. ASTM D882 -Standard Test Method for Tensile Properties of Thin Plastic Sheeting. ASTM, West Conshohocken, PA, USA.

Ashby, M.F.; Jones, D.R.H. 2007. Material Engineering. Campus, Rio de Janeiro, RJ, Brazil.

Balachandar, M.; Vijaya, B.R.; Barath, R.; Bharath, S.S. 2019. Mechanical characterization of natural fiber polymer composites. Materials Today Proceedings 16: 1006-1012. https://doi.org/10.1016/J.MATPR.2019.05.189

Dal Fabbro, I.; Gazzola, J. 2018. Viscoelasticity: A Introduction. SBEA, Jaboticabal, SP, Brazil.

Dal Fabbro, I.M.; Gazzola, J.; D`Avilla, E.; Silva, G.K.; Biasi, Â.R.; Enes, A.M.; Rodrigues, S. 2020. Physical and mechanical properties of biological materials. Revista Ciência Agronômica 51. https://doi.org/10.5935/18066690.20200099

Finney, E.E.; Hall, C.W. 1967. Elastic Properties of Potatoes. Transactions of the ASAE 10: 4-8. https://doi. org/10.13031/2013.39578
Kazemi, M.E.; Shanmugam, L.; Lu, D.; Wang, X.; Wang, B.; Yang, J. 2019. Mechanical properties and failure modes of hybrid fiber reinforced polymer composites with a novel liquid thermoplastic resin, Elium ${ }^{\circledR}$. Composites. Part A: Applied Science and Manufacturing 125: 105523. https://doi. org/10.1016/J.COMPOSITESA.2019.105523

Kohyama, K.; Takezawa, Y.; Takada, A. 2008. Effects of head size on the mechanical properties of shredded cabbage. Food Science and Technology Research 14: 541-546. https://doi. org/10.3136/fstr.14.541

Melo, R.P.; Albiero, D.; Monteiro, L.A.; Souza, F.H.; Silva, J.G. 2013. Quality in the distribution of corn seed by planters in a soil of the Ceará. Revista Ciência Agronômica 44: 94-101 (in Portuguese, with abstract in English).

Melo, R.R.; Antunes, F.L.M.; Daher, S.; Vogt, H.H.; Albiero, D.; Tofoli, F.L. 2019. Conception of an electric propulsion system for a $9 \mathrm{~kW}$ electric tractor suitable for family farming. IET Electrical Power Applications 13: 1993-2004. https://doi. org/10.1049/iet-epa.2019.0353

Mohsenin, N.N. 1986. Physical Properties of Plant and Animal Materials: Structure, Physical Characteristics, and Mechanical Properties. Gordon and Breach, New York, NY, USA.

Mohsenin, N.N. 1970. Physical Properties of Plant and Animal. Google Books, New York, NY, USA.

Montgomery, D.C. 2004. Introduction Statistical Control of Quality. 4ed. Wiley, New York, NY, USA.

Moya, M.; Aguado, P.J.; Ayuga, F. 2013. Mechanical properties fo some granular agricultural materials used in silo design. International Agrophysics 27: 181-193. https://doi.org/10.2478/ v10247-012-0084-9

Pérez-Arauz, A.O.; Agular-Rabiela, A.E.; Vargas-Torres, A.; Rodrigues-Hernadez, A.I.; Chavarria-Hernandez, N.; VergaraPorras, B.; Lopez-Cuellar, M.R. Production and characterization of biodegradable films of a novel polyhydroxyalkanoate (PHA) synthesized from peanut oil. Food Packaging and Shelf Lipe 20: https://doi.org/10.1016/j.fpsl.2019.01.001

Snedecor, G.W.; Cochran, W.G. 1989. Statistical Methods. Iowa State University, Ames, IA, USA.

Soontarapa, K.; Arnusan, J. Dehidration of paddy rice in a chitosan membrande drier. Separation and Purification Technology 209: 401-408. https://doi.org/10.1016/j.seppur.2018.07.048

Souza, R.S.; Rezende, R.; Freitas, P.S.L.; Gonçalves, A.C.A.; Rezende, G.S. 2015. Dry matter production and macronutrient leaf composition in lettuce under fertigation with nitrogen, potassium and silicon. Revista Brasileira de Engenharia Agrícola e Ambiental 19: 1166-1171. https://doi.org/10.1590/1807-1929/ agriambi.v19n12p1166-1171

Yamaguchi, M. 1983. World Vegetables: Principles, Production, and Nutritive Values. AVI, Westport, CT, USA.

Zdunek, A.; Kurenda, A. 2013. Determination of the elastic properties of tomato fruit cells with an atomic force microscope. Sensors 13: 12175-12191. https://doi.org/10.3390/s130912175

Zeltmann, S.E.; Prakash, K.A.; Doddamani, M.; Gupta, N. 2017. Prediction of modulus at various strain rates from dynamic mechanical analysis data for polymer matrix composites. Composities. Part B: Engineering 120: 27-34. https://doi. org/10.1016/j.compositesb.2017.03.062 